\title{
Why do I rate? - Shedding Light on the Factors Influencing the Participation on Physician Rating Websites
}

\author{
Maximilian Haug \\ Neu-Ulm University of Applied Sciences \\ Center for Research on Service Sciences (CROSS) \\ maximilian.haug@hs-neu-ulm.de
}

\author{
Heiko Gewald \\ Neu-Ulm University of Applied Sciences \\ Center for Research on Service Sciences (CROSS) \\ heiko.gewald@hs-neu-ulm.de
}

\begin{abstract}
Nowadays it is possible for consumers to exchange consumption experiences with everybody on the internet. For almost every product or service people form communities or visit dedicated rating websites to exchange information. Concerning medical treatment services, physician ratings have emerged as a field of interest for both patients and physicians. However, little is known about why people even spend time and effort to rate their physician. We conducted a study in which we asked patients about their intention to use physician rating websites, building on the social exchange theory. The results suggest that the main motivations to rate are to help other patients finding the right doctor or trying to influence the doctor for better treatment in the future.
\end{abstract}

\section{Introduction}

Since the Web 2.0 revolution, the Internet as a communication platform has allowed people to exchange their consumer experiences with over half the population of the planet. For example, product information, product reviews and consumer ratings can be exchanged on social media networks like Facebook, on integrated feedback systems of online shops like Amazon.com, or on dedicated rating websites like yelp.com. This type of information exchange is commonly called electronic word-ofmouth (eWOM) [7]. People are able to express their subjective opinions on products and/or services by providing a numerical rating or by articulating it in a written review. By providing ratings or reviews, consumers help other people fill the knowledge gap consumers experience prior to purchasing. However, filling this gap requires a substantial body of information. Making a decision based solely on online ratings can be dangerous because only a small share of consumers actually rate products and services online.

Whereas physical products are relatively easy to rate, rating services is more challenging because they are intangible [21]. This difficulty is compounded in healthcare and medical treatment because patients lack the necessary knowledge to evaluate their treatment appropriately and because it may take a long time or never be possible to evaluate whether a medical treatment was successful.

Only 1 out of 1,000 buyers on Amazon.com rates the product s/he purchases [17]. According to Gao et al. [11] similarly low rating rates are common on physician rating websites (PRW), which are dedicated platforms that patients can use to recommend and rate physicians based on a set of factors [19], which vary across rating websites [31].

Past research has focused heavily on the effect of eWOM on sales or on consumers' perception towards a product or service $[4 ; 5 ; 23]$. Little is known about what motivates consumers to participate actively in eWOM activities. Limited research has focused on movie ratings [8; 9; 15], but as Dellarocas et al. [8] suggest, the factors influencing eWOM participation differ depending on the what is being rated. The present study adds a further stone to the eWOM mosaic, investigating the factors that motivate patients to rate their physician online.

The most popular German physician rating website, jameda, has 6 million unique users per month and contains contact information for over 480,000 physicians and health professionals [18]. Considering the vast volume of users, its two million ratings indicate that most users use the physician rating website more as a source of information and much less as a platform to express their opinion [17].

Aside from statistics, little is known about what motivates active participation on physician rating websites. To gain a better understanding into patients rating behavior, this study asks: "What factors influence the willingness of patients to articulate their 
opinion about their medical treatment experience on physician rating websites?"

An analysis of quantitative data collected by interviewing patients in physician waiting rooms indicates that expected intrinsic benefits motivate patients to rate their physicians online. While social exchange theory provides high explanatory power in other eWOM contexts, the findings in this study show a weak $\mathrm{R}^{2}$ and indicate the need for $\mathrm{a}$ complementary theory to better explain the factors that motivate or restrict patient participation in eWOM.

The paper is structured as follows. First a review of relevant and related literature is provided. Then the research model is explicated and the research method and results are presented. The paper closes with a discussion of its theoretical and practical implications, as well as limitations, suggestions for further research and conclusions.

\section{Literature Review}

\section{1 eWOM and Physician Rating Websites}

Word-of-mouth is defined as the face-to-face exchange of information among consumers regarding products, services or brands [1]. Since the advent of web 2.0 information technologies, word-of-mouth is no longer restricted to physical interaction with friends, family or colleagues. Hennig-Thurau et al. [15] derive the factors driving motivation to participate in electronic word-of-mouth from traditional word-of-mouth literature. The authors take a holistic approach and discuss eight factors leading to participation in eWOM: platform assistance, venting negative feelings, concern for other consumers, positive self-enhancement, social benefits, economic incentives, helping the company and seeking advice. Since the physician rating website chosen for this study, jameda, the largest German online physician rating platform, does not provide economic incentives and reviewers are anonymous, self-enhancement, in terms of increasing one's reputation, and economic incentives are not applicable.

To date, eWOM literature has not identified the factors leading to active participation. Most studies focus predominantly on the effects of eWOM, such as the impact on purchase decisions and sales of specific products such as books or movies [5; 12; 23]. Only few studies, such as Gao et al. [12], consider the context of physician ratings.

\subsection{Theories of information contribution}

Social exchange theory (SET) explains human behavior based on social exchange [3]. Social exchange between parties does not have a direct return, but, rather, is seen as part of a long-term social relationship. Social exchange theory hypothesizes that people act to minimize their costs and maximize their benefits [26]. Negative outcomes, cognitive effort or time spent are examples of the cost of a social exchange, whereas rewards, reciprocal benefits or reputation improvements are examples of intrinsic or extrinsic benefits that motivate social exchange [20; 27].

Gruen et al. [13] state that different forms of eWOM can have different values for the participants, such as economic, social or utilitarian values. By nature, knowledge contribution on the Internet or knowledge contribution to dedicated knowledge repositories are similar in that both can be viewed through the lens of social exchange theory.

Since most research into social exchange theory evaluate data using structural equation modelling with a partial least squares method, they can be compared and implications can be drawn for further research questions. Kankanhalli et al. [20] researched factors motivating contribution to knowledge repositories in a corporate context. They argue that knowledge management is insufficient because employees are reluctant to contribute knowledge to the system. Their study in Singapore over 6 months in 2002 collected 150 responses from 10 organizations. The results show that costs, extrinsic benefits and intrinsic benefits predict knowledge contribution to electronic knowledge repositories. Especially intrinsic benefits significantly affect usage.

Wasko and Faraj [39] investigated knowledge contribution in electronic networks of practice, which are computer mediated forums of common interest for discussing the problems people have in practice. They apply social exchange theory and social capital theory to determine what motivates strangers to help other people by contributing knowledge without direct return. The study surveyed 173 active participants on an electronic practice network maintained by a professional legal association in the United States. In contrast to Kankanhalli et al. [20], intrinsic benefits such as the enjoyment of helping others did not influence participation behavior. This discrepancy suggests social exchange theory may or may not explain participation behavior, depending on the context.

Tong et al. [37] researched the factors that influence the intention to participate in online 
feedback systems. The authors distinguish between cost and benefit factors as suggested by Molm [26], whereas benefits were grouped into intrinsic, extrinsic and internalized extrinsic factors. Internalized extrinsic benefits share characteristics with gaining reputation, as discussed by Kankanhalli et al. [20]. Tong et al. [37] describe it as selfenhancement in the online community. Their results identify the enjoyment of helping others as a significant predictor of contributing information to feedback systems. Another factor motivating eWOM participation was the desire to influence the company providing the product or service. Executional cost, the effort and time needed to contribute information were found to negatively affect participation intention. The predictive power of their model is similar to Kankanhalli et al. [20], which suggests, that social exchange theory may be applicable in the eWOM context.

Pi et al. [27] focused, similar to Tong et al. [37], on the eWOM context, investigating the factors influencing what they call "eWOM intention", which is the intention to contribute experiences about products and services on social networking sites (SNS), relying on social exchange theory and social capital theory. The authors hypothesized that a set of factors are influencing affective and cognitive attitudes which ultimately influence SNS users' intention to participate in eWOM. They define affective attitude as the emotional attraction to SNS and the cognitive attitude as the degree to which an individual develops certain believes towards SNS. Their results show that only the cognitive component significantly influences eWOM intention. In contrast to Tong et al. [37] and in line with Wasko and Faraj [39], the intrinsic benefit enjoyment of helping others was found to be insignificant. However, trust, motivation and ability to exchange information over the Internet were found to influence cognitive attitudes.

Tsai and Bagozzi [38] adapted the theory of planned behavior to assess influences on weintentions, which ultimately affects contribution behavior in virtual communities. A we-intention is described as “a collective intention rooted in person's self-conception as a member of a particular group (e.g., an organization) or social category (e.g., one’s gender, one's ethnicity), and action is conceived as either the group acting or the person acting as an agent of, or with, the group” [2]. Tsai and Bagozzi [38] research focuses on small-group dynamics within a greater community. In the context of physician ratings, this approach was rejected because the anonymous environment does not leave room for emerging group dynamics or leveraging information contributions in terms of eWOM. The same applies to the research of Shi et al. [34], who researched content contribution on Twitter and retweet behavior. This research also applied social exchange theory. Their results show that weak ties predict social exchange. Even though characteristics of eWOM differ from physician rating websites, Shi et al. [34] present yet another context in which social exchange theory is highly explanatory.

In summary, the literature review showed that social exchange theory can be applied to the context of information and or content contribution in general, as well as to eWOM. However, even within social exchange theory the relevant influences have to be newly defined or excluded to fit a context lacking extrinsic benefits, as is the case for the current research environment.

\section{Research Model}

The research model depicted in Figure 1 is based on Tong et al. [37] with the inherent focus on the influences of benefits and costs on intention. Their original constructs were altered to fit the context of physician rating websites. The definition of eWOM intention is adapted from Pi et al. [27] and altered to focus solely on physician rating websites. For the influences on the eWOM intention the framework of Tong et al. [37] is adapted with its intrinsic benefits and the cognitive and executional costs, such as suggested in social exchange theory. Since selfenhancement requires the possibility to gain reputation and benefits on internet platforms, it is excluded from our research model because our target physician rating platform only posts anonymous ratings and because raters do not receive economic rewards.

Tong et al. [37] identify the enjoyment of helping others as factor influencing the intention of people to contribute to an information exchange. In their research model, the enjoyment of helping other consumers is categorized as a benefit that emerges from an intrinsic motivation. Shih et al. [35] include the concept of altruism in the construct of motivation and view it as a motivator to engage in eWOM. Accordingly, a highly motivated consumer is willing to engage in valuable exchanges with others and will therefore produce meaningful reviews.

H1: The enjoyment of helping other patients positively influences eWOM intention.

Similarly, Tong et al. [37] identifies the enjoyment of influencing the company as an intrinsic 


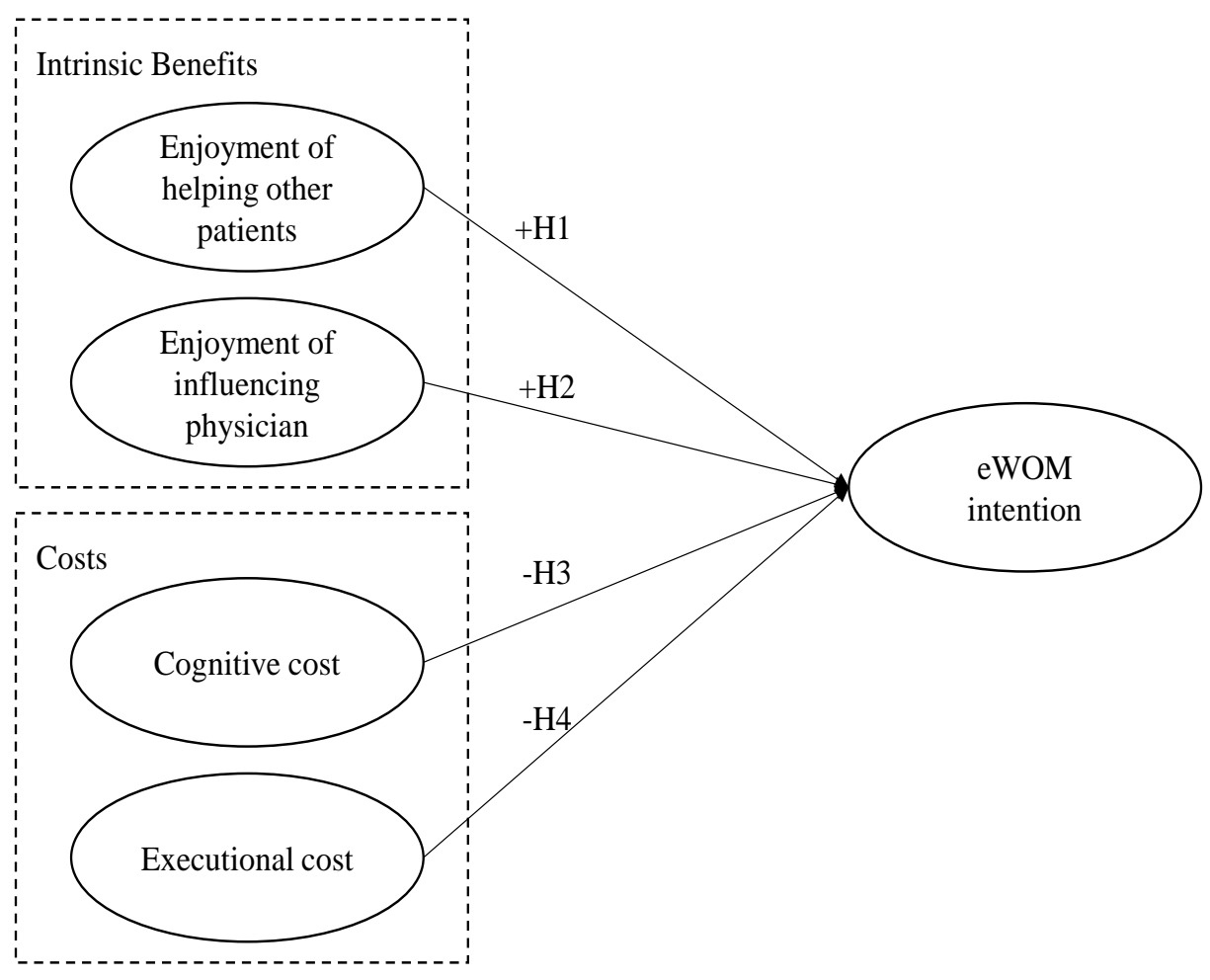

Figure 1. Research Model

benefit. In terms of the motivation, the altruistic help is aimed towards the company, which is substituted in our model by the physician. Since patients may enjoy influencing their physician, we hypothesize:

H2: The enjoyment of influencing one's physician positively influences eWOM intention.

The construct of cognitive cost is mentioned by Tong et al. [37] with regard to eWOM intention because creating a review requires reviewers to recall past experiences of using a service or a product. According to psychologists [10], this complex cognitive process can lead to annoyance or unpleasantness and ultimately represent an intrinsic cost to the potential reviewer. We therefore hypothesize:

H3: Cognitive cost negatively influences eWOM intention.

Tong et al. [37] also suggest the construct of executional cost as a predictor of eWOM intention, describing the "materialization" of the review in the real world as a time demand. The reviewer has to spend time and effort to access the review system and type the detailed product review. The time demand is described as substantial when providing detailed reviews. The term cost is used because of the fact the potential reviewer could spend that time doing something else which might provide more pleasure or benefit. Therefore, executional cost is a predictor of not participating in eWOM. Thus:

H4: Executional cost negatively influences eWOM intention.

\section{Research Method}

Data was collected in southern Germany in physicians' waiting rooms. In total, five physicians were chosen in rural and urban areas. The constructs were measured reflectively by three items each on a 5-point Likert scale. A questionnaire was developed by adapting the items used by Tong et al. [37] and Shih et al. [35] to fit the context of this study. A pretest was conducted to verify that all questions were understood by participants. In addition, the questionnaire was discussed with the doctors involved in the study.

The research team was in direct contact with participants. In some cases, doctors provided a separate room in which the participants could fill in the questionnaire before their appointment. This way it was possible to also directly talk to patients to gather additional information beyond the scope of the questionnaire. 
Table 1. Cronbach's Alpha, CR, AVE, Fornell-Larcker Criterion

\begin{tabular}{|l|l|l|l|l|l|l|l|l|}
\hline & $\begin{array}{l}\text { Cronbach's } \\
\text { Alpha }\end{array}$ & CR & AVE & $\begin{array}{l}\text { Cognitive } \\
\text { cost }\end{array}$ & $\begin{array}{l}\text { Enjoy } \\
\text { helping }\end{array}$ & $\begin{array}{l}\text { Enjoy } \\
\text { influencing }\end{array}$ & Exec. cost & $\begin{array}{l}\text { eWOM } \\
\text { intention }\end{array}$ \\
\hline Cognitive cost & 0.894 & 0.934 & 0.826 & 0.909 & & & & \\
Enjoy helping & 0.791 & 0.867 & 0.686 & -0.267 & 0.828 & & & \\
Enjoy infl. & 0.725 & 0.832 & 0.623 & -0.209 & 0.568 & 0.789 & & \\
Executional cost & 0.865 & 0.917 & 0.786 & 0.213 & -0.267 & -0.115 & 0.887 & \\
eWOM Intention & 0.860 & 0.914 & 0.781 & -0.110 & 0.412 & 0.365 & -0.126 & 0.884 \\
\hline
\end{tabular}

The areas of expertise of the physicians ranged from general practitioners (24 responses), to otolaryngologists (47 responses), and orthopedists (44 responses). The data shows a relatively even distribution among age and income.

All measures were self-reported, therefore there is a potential for common method bias [29]. Statistical analyses were performed to assess whether common method bias is an issue in the data set. A Harman one-factor test [29] was conducted on the four constructs of the research model. The test results show that four factors were identified, with the biggest factor explaining only $30 \%$ of the covariance. This indicates that common method bias is not likely. Following Podsakoff et al. [28] and Williams et al. [40] a common method factor was included in the PLS model which includes all construct indicators. Additionally, all factors were transformed into singleitem constructs. Afterwards the coefficient of determination $\left(\mathrm{R}^{2}\right)$ with the common method factor and without the common method factor were compared. The difference between the coefficients show a value of 0.0046 , without the factor the $\mathrm{R}^{2}$ is 0.752 , which shows a ratio of $1: 164$. This ratio is above 1:42 of Liang et al. [22] and 1:154 of Maier et al. [24]. Therefore, we conclude that common method bias is not an issue with our data.

VIF (Variance inflation factor) values of independent constructs were checked. As a rule of thumb in multicollinearity evaluation VIF values of the predictor construct must be lower than 5 [25]. The values range between 1.106 and 1.605 which indicates that multicollinearity was not an issue in this study.

\section{Research Results}

The Structural equation modelling (SEM) technique using partial least squares (PLS) was used to assess the results. SmartPLS 3.2.7 [32] was used to evaluate the data. With a sample size of $n=115$ there were relatively few data points. However, following the rule of ten [14] only 40 filled questionnaires were needed. Since the rule of ten is argued to give too rough estimates for the minimum sample size, Hair $\mathrm{Jr}$ et al. [14] suggests a second method to assess the sample size, by taking estimates for the minimum explanatory power of the model $\mathrm{R}^{2}$ into account. By reviewing the literature, $\mathrm{R}^{2}$ between 0.19 [39] and 0.52 [20] were found in the context of social exchange theory in the online world. If we estimate a minimum $\mathrm{R}^{2}$ of 0.25 , which lies between the two found values, the minimum R-squared method estimates the minimum sample size at 41 participants. Furthermore, if a more challenging approach would be applied and a weak $\mathrm{R}^{2}$ of only 0.1 was assumed, the method recommends a sample size of at least 113, which is also exceeded by this study.

Internal consistency reliability was assessed through Cronbach's Alpha and composite reliability (CR). Cronbach's Alpha is a conservative criterion, whereas composite reliability takes into account the different outer loadings. Therefore, both can be taken as boundaries for the reliability. Cronbach's Alpha

Table 2. Heterotrait-Monotrait Ratio

\begin{tabular}{|l|l|l|l|l|l|}
\hline & $\begin{array}{l}\text { Cognitive } \\
\text { cost }\end{array}$ & $\begin{array}{l}\text { Enjoy } \\
\text { helping }\end{array}$ & $\begin{array}{l}\text { Enjoy } \\
\text { influencing }\end{array}$ & $\begin{array}{l}\text { Executional } \\
\text { cost }\end{array}$ & eWOM intention \\
\hline Cognitive cost & & & & & \\
Enjoy helping & 0.309 & & & & \\
Enjoy influencing & 0.267 & 0.812 & & & \\
Executional cost & 0.237 & 0.310 & 0.145 & & \\
eWOM intention & 0.126 & 0.443 & 0.414 & 0.141 & \\
\hline
\end{tabular}


typically presents lower values, while CR overestimates the internal consistency reliability. Values above 0.70 are desirable, whereas values above 0.95 are not desired, since it indicates that all indicators measure the same phenomenon [14]. Table 1 shows that neither the values of Cronbach's Alpha nor CR exceed those boundaries.

Convergent validity was assessed by the average variance extracted (AVE) and by observing the factor loadings. For the AVE, values of above 0.5 indicate convergent validity [14], which is the case as can be seen in Table 1. In addition, the factor loadings, are all above the threshold of 0.708 [14] and significant at the 0.001 level. Based on these criteria convergent validity can be concluded for this research model.

Discriminant validity was assessed by three criteria. First the cross-loadings were observed to show that the indicators correlate with their respective construct the most. Second, the FornellLarcker criterion was applied to assess discriminant validity. Table 1 shows that the highest value can be found for the respective construct on the top. Therefore, the criterion indicates discriminant validity. Lastly, the heterotrait-monotrait ratio as a criterion was observed, which can be seen in Table
2.Values above 0.90 are considered to not show discriminant validity [14]. A more conservative threshold is the value of 0.85 [16]. In this case all values are below the thresholds. Therefore, based on the presented three criteria, we can conclude discriminant validity for this model.

Figure 2 depicts the results of the structural equation modelling with the path coefficients, effect size and explanatory power of the model.

Enjoyment of helping other patients shows a significant impact on the eWOM intention $(\beta=0.299$, $\mathrm{p}<0.05$ ) with an effect size of $\mathrm{f}^{2}=0.069$. Furthermore, enjoyment of influencing one's physician was also found as significant influence $(\beta=0.195, p<0.05)$ with an effect size of $\mathrm{f}^{2}=0.032$. Therefore, all intrinsic benefits, which where hypothesized in the beginning show an influence, which supports $\mathrm{H} 1$ and $\mathrm{H} 2$. On the other hand, neither cognitive cost $(\beta=0.016$, n.s. $)$ nor executional cost ( $\beta=-0.027$, n.s.) were found to be significant influences. Therefore, both costs which were hypothesized to influence the eWOM intention were not found significance and $\mathrm{H} 3$ and $\mathrm{H} 4$ are not supported.

The model is able to explain $19.6 \%$ of the

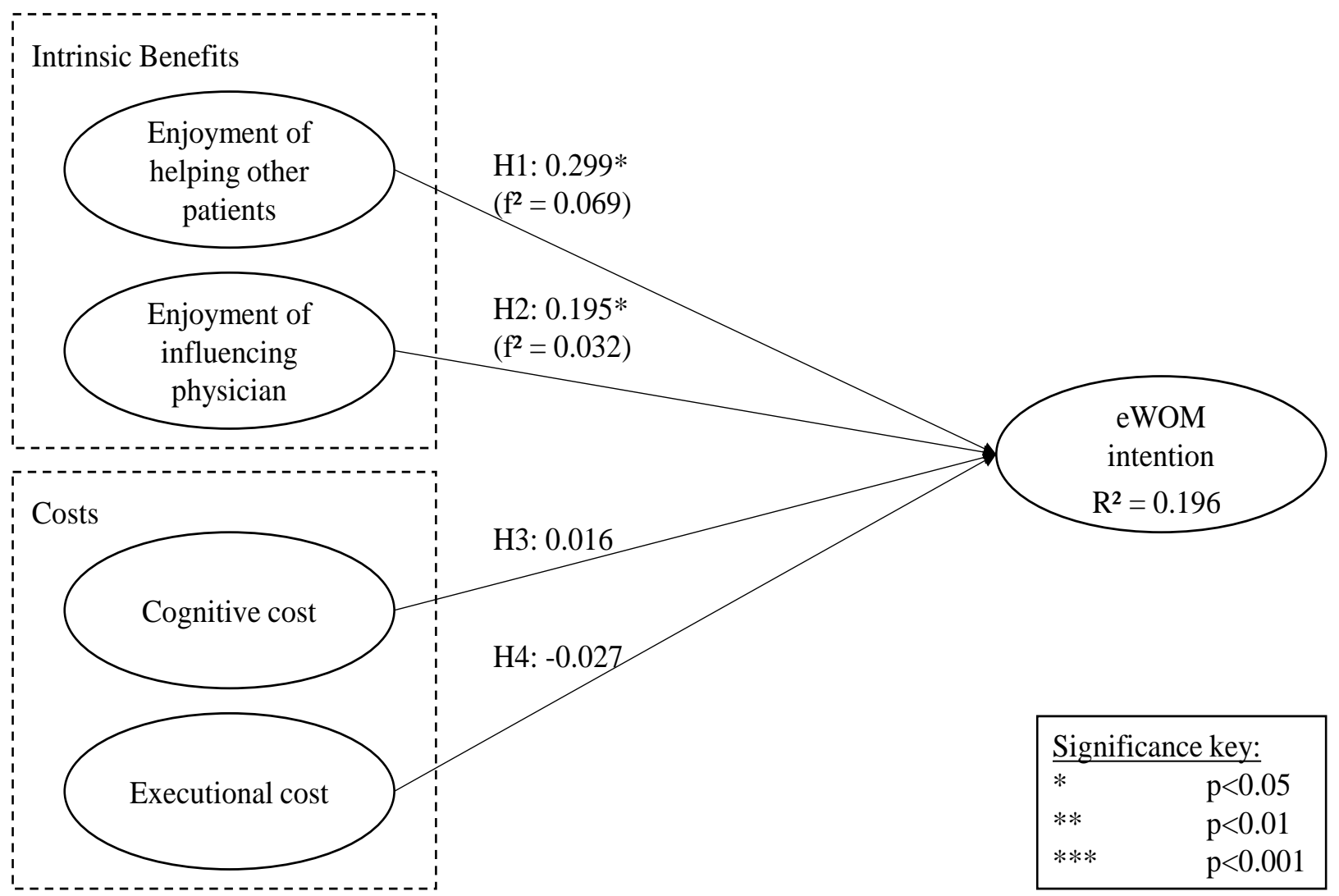

Figure 2. Research Results 
variance in eWOM intention. This result is considered weak according to Chin [6].

\section{Discussion}

The results of this research are not as expected, since the explanatory power of the model is unsatisfactory $\left(\mathrm{R}^{2}=19.6 \%\right)$. Based on the literature, the model should provide a robust result and explain variances in the range of $45 \%-52 \%$ in the context of eWOM [27; 37].

Thus, the question arises, what is it about the physician ratings research setting that weakens the explanatory power of the applied theory? One explanation could be that in medical treatment service, in contrast to many other services, the "consumer" of the medical treatment service has a close relation to the service provider, the physician. It is often necessary for the patient to provide intimate personal information to improve the quality of the treatment. Due to this personal information, people need more intimate trust in a physician than, say, in a barber or a mechanic.

In addition, the outcome of the service is difficult to evaluate. The patient hopes to improve her/his personal condition by visiting a general practitioner. However, the process of improving well-being is not finished at the end of the doctor visit, but usually takes much longer. This is also different from most services in which the consumer can see direct differences after the service is provided. Since most patients are medical laymen who are not able to evaluate the treatment objectively, the perceived satisfaction is often less strongly driven by technical quality than by the interpersonal relationship between patient and physician. The intrinsic benefit of helping others would lead patients to help other people to find a physician who is friendly or warn others about physicians who are rude or impolite. Due to the subjective nature of these characteristics, patients might not see the worth of spreading this kind of information, since different patients might perceive the physician in a different light. The construct of enjoying influencing towards the one's physician implicates that the patients want to express their gratitude for good treatment. The definition of a good treatment is questionable in this case, since, as mentioned, patient typically evaluate treatment based on interpersonal aspects. So, patients cannot be sure to be treated in the right way and therefore are more reserved in praising their physician in the form of good ratings.

Following this logic, patients may see that rating a physician directly after a visit may not provide much information about the quality of the physician.
Since doctors are typically rated based on interpersonal aspects and treatment does not have an immediate outcome, the effort to recall the experience (cognitive cost) is not an issue for patients. The descriptive statistics show low mean overall cognitive cost. Therefore, cognitive cost does not constrain eWOM intention, but also does not leverage it. The executional cost also does not prevent patients from contributing information, which is in line with the argumentation that patients might not consider their personal rating useful and therefore spend their time and effort doing something else.

As a last big difference for German patients, the characteristic of the financial circumstances might also influence how people perceive the medical treatment. In the U.S. patients have to pay for the medical treatment services, while in Germany almost all Germans have statutory health insurance, which covers the cost of visiting a general practitioner. Therefore, German patients are able to visit multiple doctors without suffering financial damage. This way it is possible for patients to experience the service themselves instead of relying on ratings. This preference for experiencing the service personally might reduce the willingness to contribute information because of the assumption that others think the same, which reduces the perceived value of the information the patient wanted to contribute.

\subsection{Theoretical Implications}

This study advances theoretical development in eWOM and especially in the better understanding of the use of physician rating websites. It is, to our knowledge, the first paper which attempts so explain what motivates patients to rate their doctor online. Based on the literature, social exchange theory was tested to assess whether the given factors can be applied to this context. The research shows that intrinsic benefits can predict the intention to participate on PRWs. However, social exchange theory alone cannot explain why people actively review on physician rating websites. Therefore, a complementary theory is needed to analyze this phenomenon holistically. Social capital theory with trust, norms and identification as further enablers for eWOM participation can complement the model, as demonstrated by Kankanhalli et al. [20].

The results show what influences likely do not impact the decision whether to rate. The defined costs do not impact the eWOM intention. Therefore, people do not choose not to rate because they lack the time or because other tasks have a higher priority, but 
since most people do not rate online, there must be other restrictors.

This research reveals that people probably do not make decisions solely by weighing costs and benefits. The social exchange theory should therefore be extended by factors which take emotional states and attitudes towards the object into account. The framework of Pi et al. [27] shows a first step by investigating how different factors influence the cognitive and affective attitude of the observed object and how these ultimately affect the intention to participate in eWOM. This is in line with the specifics of the encounter with the physician, which mostly comes down to the interpersonal relationship with the patient and not the objective evaluation of the treatment quality.

Our encounters with patients gave some insights into how to tackle this issue. The perception of rating platforms proved very negative in Germany. In addition, a lot of patients knew that there is the possibility to rate online but could not articulate exactly where. The usefulness is not or rarely seen by patients, which could influence participation behavior. Furthermore, the demographic variables show a relatively even distribution of the age. However, given the small sample size, it is possible that this distribution does not reflect the true patient age distribution. Terlutter et al. [36] argued that digitally literate people usually have a better attitude towards physician rating websites than digitally illiterate people, which tends to be an issue for elderly people [30].

\subsection{Practical Implication}

The research in the field of physician ratings has important implications for practitioners. Since past research on eWOM has shown to influence decisionmaking $[15 ; 41]$, it is in the interest of physicians to make sure that their treatment service is represented online. Past research showed that physicians get mostly favorable rating [19]. More ratings would therefore increase the reputation, due to the overwhelming positive feedback, but also in terms of quantity. A physician with many ratings will be seen as in higher demand and will be associated with better quality. Lin et al. [23] showed the connection between the volume of eWOM and people's perceptions. The more patients giving an online rating, the better the overall perception of the physician. Our study indicates that patients have reservations about providing information about their medical treatment online, so physicians should motivate their patients to provide information. By explaining the relevance of ratings to patients, physicians might increase patients' intention to rate online.

In our interviews, many patients articulated their confusion about why they should even rate, even though they used rating platforms as an information source. So there is a heavy discrepancy in how people use these platforms in terms of information gathering and information providing. If more patients knew that more ratings increase the information quality by reducing bias, such as negative experience bias, the intention to rate might increase. $\mathrm{Hu}$ et al. [17] showed that ratings are subject to self-selection biases. Even though most people give favorable ratings, the prevalence of negative ratings is still high in comparison [19]. Physicians should view the option of using rating websites as a tool for patients to make appointments [33]. This is a possibility to make medical treatment more efficient by making more time available for treatment and to attract a broader patient basis.

\section{Limitations and Further Research}

The relatively small sample size of our study and number of participating physicians limit the results of our research by nature. In addition, given regional differences in attitudes towards open criticism, since only patients in southern Germany were asked our findings cannot necessarily be generalized to all of Germany.

Our study underscores the need for a complementary theory to increase the explanatory power of the research model. As discussed above, the resources trust, norms and identification included in social capital theory may be tested as moderating variables on benefits and/or costs. Future research may investigate whether people take a more rational or a more emotional approach they go online with the intention to rate. This would involve asking people who have rated physicians in the past to report their motivations. Since only one participant in this study actively rated online, eWOM intention was only hypothetical. Future studies should more actively target information providers.

Finally, our results suggest that patients might withhold rating information they perceive as not valuable because it is based on interpersonal aspects of the doctor visit rather than objective evaluation criteria. Further research should therefore identify the attitudes of patients towards physician ratings in general. 


\section{Conclusion}

This research represents a first step toward understanding the factors influencing patients' intentions to rate their doctors online. Practical implications can be drawn based on the significance of the intrinsic benefits, such as enjoyment of helping other patients and enjoyment of influencing one's physician. In addition, the non-significance of executional and cognitive cost reveals initial insights into patients' thought processes. The study shows that modified social exchange theory alone insufficiently explains this phenomenon and that a refined research model is needed which considers additional online rating enablers and restrictors.

\section{Appendix}

Table 3. Questionnaire

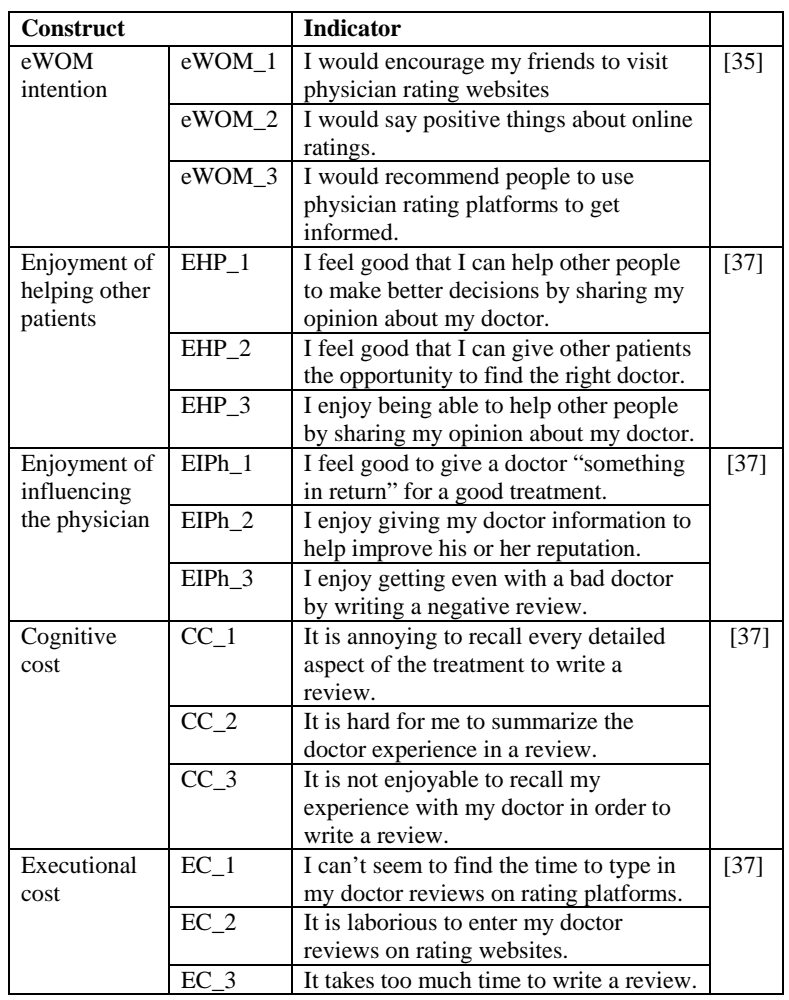

\section{References}

[1] Arndt, Johan; Word of mouth advertising: A review of the literature, Advertising Research Foundation, 1967.

[2] Bagozzi, Richard P; Consumer Action in: Review of marketing research, Emerald Group Publishing Limited, 2006, pp. 3-42.
[3] Blau, Peter Michael; Exchange and power in social life, Transaction Publishers, 1964.

[4] Chen, Yubo and Xie, Jinhong; Third-party product review and firm marketing strategy, Marketing Science, (24:2), 2005, pp. 218-240.

[5] Chevalier, Judith A and Mayzlin, Dina; The effect of word of mouth on sales: Online book reviews, Journal of marketing research, (43:3), 2006, pp. 345-354.

[6] Chin, Wynne W; The partial least squares approach to structural equation modeling, Modern methods for business research, (295:2), 1998, pp. 295-336.

[7] Chu, Shu-Chuan and Kim, Yoojung; Determinants of consumer engagement in electronic word-of-mouth (eWOM) in social networking sites, International journal of Advertising, (30:1), 2011, pp. 47-75.

[8] Dellarocas, Chrysanthos; Gao, Guodong and Narayan, Ritu; Are consumers more likely to contribute online reviews for hit or niche products?, Journal of Management Information Systems, (27:2), 2010, pp. 127158.

[9] Dellarocas, Chrysanthos and Narayan, Ritu; What motivates consumers to review a product online? A study of the product-specific antecedents of online movie reviews, WISE, 2006.

[10] Fiske, Susan T and Taylor, Shelley E; Social cognition: From brains to culture, Sage, 2013.

[11] Gao, Guodong (Gordon); McCullough, Jeffrey; Agarwal, Ritu and Jha, Ashish; A Changing Landscape of Physician Quality Reporting: Analysis of Patients' Online Ratings of Their Physicians Over a 5-Year Period, Journal of Medical Internet Research, (14:1), 2012, pp. 111.

[12] Gao, Guodong Gordon; Greenwood, Brad N; Agarwal, Ritu and McCullough, Jeffrey S; Vocal minority and silent majority: How do online ratings reflect population perceptions of quality?, MIS quarterly, (39:3), 2015, pp. 565-589.

[13] Gruen, Thomas W; Osmonbekov, Talai and Czaplewski, Andrew J; eWOM: The impact of customerto-customer online know-how exchange on customer value and loyalty, Journal of Business research, (59:4), 2006, pp. 449-456.

[14] Hair Jr, Joseph F; Hult, G Tomas M; Ringle, Christian and Sarstedt, Marko; A primer on partial least squares structural equation modeling (PLS-SEM), Sage Publications, 2016.

[15] Hennig-Thurau, Thorsten; Gwinner, Kevin P; Walsh, Gianfranco and Gremler, Dwayne D; Electronic word-of-mouth via consumer-opinion platforms: What motivates consumers to articulate themselves on the Internet?, Journal of interactive marketing, (18:1), 2004, pp. 38-52.

[16] Henseler, Jörg; Ringle, Christian $M$ and Sarstedt, Marko; A new criterion for assessing discriminant validity in variance-based structural equation modeling, Journal of the academy of marketing science, (43:1), 2015, pp. 115-135.

[17] Hu, Nan; Pavlou, Paul A and Zhang, Jie; On SelfSelection Biases in Online Product Rreviews, MIS Quarterly, (41:2), 2017, pp. 449-471. 
[18] jameda (2017). jameda Factsheet, https://www.jameda.de/jameda/jameda/jamedaFactsheet.pdf.

[19] Kadry, Bassam; Chu, F. Larry; Kadry, Bayan; Gammas, Danya and Macario, Alex; Analysis of 4999 Online Physician Ratings Indicates That Most Patients Give Physicians a Favorable Rating, Journal of Medical Internet Research, (13:4), 2011, pp. e95.

[20] Kankanhalli, Atreyi; Tan, Bernard CY and Wei, Kwok-Kee; Contributing knowledge to electronic knowledge repositories: an empirical investigation, MIS Quarterly, (29:1), 2005, pp. 113-143.

[21] Klein, Lisa R; Evaluating the potential of interactive media through a new lens: Search versus experience goods, Journal of business research, (41:3), 1998, pp. 195-203.

[22] Liang, Huigang; Saraf, Nilesh; Hu, Qing and Xue, Yajiong; Assimilation of enterprise systems: the effect of institutional pressures and the mediating role of top management, MIS quarterly, (31:1), 2007, pp. 59-87.

[23] Lin, Chin-Lung; Lee, Sheng-Hsien and Horng, DerJuinn; The effects of online reviews on purchasing intention: The moderating role of need for cognition, Social Behavior and Personality: an international journal, (39:1), 2011, pp. 71-81.

[24] Maier, Christian; Laumer, Sven; Eckhardt, Andreas and Weitzel, Tim; Giving too much social support: social overload on social networking sites, European Journal of Information Systems, (24:5), 2015, pp. 447-464.

[25] Mansfield, Edward R and Helms, Billy P; Detecting multicollinearity, The American Statistician, (36:3a), 1982, pp. 158-160.

[26] Molm, Linda D; Coercive power in social exchange, Cambridge University Press, 1997.

[27] Pi, Shih-Ming; Liao, Hsiu-Li and Liu, Su-Houn; The Effect of Social Relationships, Social Exchange, and Motivation and Ability to Access Information on Electronic Word-of-Mouth in Social Networking Sites, Pacific Asia Conference on Information Systems, 2016.

[28] Podsakoff, Philip M; MacKenzie, Scott B; Lee, JeongYeon and Podsakoff, Nathan P; Common method biases in behavioral research: a critical review of the literature and recommended remedies, Journal of applied psychology, (88:5), 2003, pp. 879.

[29] Podsakoff, Philip M and Organ, Dennis W; Selfreports in organizational research: Problems and prospects, Journal of management, (12:4), 1986, pp. 531544.

[30] Prensky, Marc; Digital natives, digital immigrants part 1, On the horizon, (9:5), 2001, pp. 1-6.

[31] Reimann, Swantje and Strech, Daniel; The representation of patient experience and satisfaction in physician rating sites. A criteria-based analysis of English- and German-language sites, BMC Health Services Research, (10:1), 2010, pp. 332.

[32] Ringle, Christian; Wende, Sven and Becker, JanMichael (2015). SmartPLS. Boenningstedt: SmartPLS. Retrieved from http://www.smartpls.com.

[33] Schaarschmidt, Mario; Ivens, Stefan and Homscheid, Dirk; Dr. Miller or Dr. Smith? Patients' Intentions to
Make Appointments on Physician Rating Platforms, International Conference on Information Systems, 2017.

[34] Shi, Zhan; Rui, Huaxia and Whinston, Andrew B; Content sharing in a social broadcasting environment: evidence from twitter, MIS quarterly, (38:1), 2013, pp. 123-142.

[35] Shih, Hung-pin; Lai, Kee-hung and Cheng, T. C. E.; Informational and Relational Influences on Electronic Word of Mouth: An Empirical Study of an Online Consumer Discussion Forum, International Journal of Electronic Commerce, (17:4), 2013, pp. 137-166.

[36] Terlutter, Ralf; Bidmon, Sonja and Röttl, Johanna; Who Uses Physician-Rating Websites? Differences in Sociodemographic Variables, Psychographic Variables, and Health Status of Users and Nonusers of PhysicianRating Websites, Journal of Medical Internet Research, (16:3), 2014, pp. 97.

[37] Tong, Yu; Wang, Xinwei and Teo, Hock-Hai (2007). Understanding the Intention of Information Contribution to Online Feedback Systems from Social Exchange and Motivation Crowding Perspectives. Hawaii International Conference on System Sciences, IEEE Computer Society: 28.

[38] Tsai, Hsien-Tung and Bagozzi, Richard P; Contribution Behaviour in Virtual Communities: Cognitive, Emotional, and Social Influences, MIS Quarterly, (38:1), 2014, pp. 143-163.

[39] Wasko, Molly McLure and Faraj, Samer; Why should I share? Examining social capital and knowledge contribution in electronic networks of practice, MIS quarterly, (29:1), 2005, pp. 35-57.

[40] Williams, Larry J; Edwards, Jeffrey R and Vandenberg, Robert J; Recent advances in causal modeling methods for organizational and management research, Journal of management, (29:6), 2003, pp. 903936.

[41] Yim, Dobin; Khuntia, Jiban; Lim, Sanghee and Duan, Wenjing; To Ask or Not To Ask? An Investigation of User Engagement and Doctor-Seeking Decision in Online Health Infomediary, International Conference on Information Systems, 2017. 